\title{
STRUCTURAL BEHAVIOR OF NON-DUCTILE REINFORCED CONCRETE COLUMNS
}

\author{
*Ari Wibowo ${ }^{1}$ and Rizki Amalia Tri Cahyani ${ }^{2}$ \\ ${ }^{1}$ Department of Civil Engineering, Faculty of Engineering, Brawijaya University, Malang, Indonesia \\ ${ }^{2}$ Department of Civil Engineering, Muhammadiyah University, Malang, Indonesia
}

*Corresponding Author, Received: 20 Dec. 2019, Revised: 17 April 2020, Accepted: 24 April 2020

\begin{abstract}
Confinement of columns with non-seismic detailing is prevalent in many old buildings and common in current detailing practice in many developing countries. This type of columns is believed to have a very low drift capacity from a conventional design perspective. To investigate the lateral load-drift behavior and the collapse mechanism of such columns, the experimental tests on four lightly reinforced concrete columns with light transverse reinforcement ratio have been undertaken. The quasi-static tests were applied on concrete columns with various longitudinal reinforcement ratio, transverse reinforcement ratio, and lap splice position. Interestingly, the results showed that the total drift capacities could reach up to $7 \%$ well beyond the required maximum drift suggested by many codes despite the low detailing. Reasonably, the closer the stirrups spacing, the higher the ductility of the columns. Whereas, it appeared that the higher the longitudinal reinforcement ratio, the lower the ductility ratio. Furthermore, the theoretical analyses have been conducted to estimate the lateral load-deflection behavior of the columns which were in a good agreement with the test results.
\end{abstract}

Keywords: Lightly reinforced columns, Transverse reinforcement, Seismic performance

\section{INTRODUCTION}

Non-ductile concrete columns are commonly found on construction practices in many developing countries [1]. This type of columns is generally designed to withstand gravity load without ductile detailing which are characterized with low transverse reinforcement ratio, inadequate development length of steel reinforcement, and improper lap splice position. It is believed that such configurations result in poor behavior of column when subjected to lateral load such as earthquake. Many studies [2-7] showed that the seismic responses of columns with inadequate detailing primarily are controlled with column shear failure which can occur in two mechanism: a) before the flexural yield point resulting in the propagation of dominant diagonal shear crack, or b) after the flexural yield point resulting in shear capacity degradation with the increase of ductility.

To fully understand the seismic performances of concrete columns subjected with lateral loads, previous studies have comprehensively investigated the effect of various column parameters on the column behaviour and collapse mechanism. Sezen [8] observed that by increasing the applied axial load, the lateral strength increased and the displacement capacity decreased whilst the loading history did not appear to affect the column lateral drift capacity. Whereas, Rodsin [9] found that the drift capacities of columns with smaller aspect ratios were similar or even larger than those with the larger aspect ratio. It was shown that this was due to additional rotation at shear cracks which increased the drift capacity of the columns. Furthermore, Griffith et al [10] tests resulted that the columns with high slenderness ratio were still able to sustain axial load even after extensive concrete crushing and effectively zero lateral load capacity. Nakamura and Yoshimura [11] showed that the effect of the axial load ratio on the shear-dominated column was found very significant. Increasing the axial load ratio from 0.18 to 0.27 decreased the lateral drift capacity from $20.6 \%$ to $3.0 \%$ for monotonic lateral loading and from $10.4 \%$ to $4.8 \%$ for cyclic lateral loading. Moreover, Yoshimura et al [12] concluded that: a) the decrease of longitudinal reinforcement ratio from $\rho_{\mathrm{v}}=1.69 \%$ to $0.94 \%$ increased the axial load drift capacity significantly from $2.0 \%$ to $17.8 \%$; b) interestingly, the research showed that short columns with $0.21 \%$ transverse reinforcement could provide considerable drift capacity compared with flexure-dominated columns. Kogoma et al [13] study showed that an increase in transverse steel ratio increased the drift capacity and shifted the failure mode from a shear failure to a flexuredominant failure mode. It appeared from those studies that the lateral load-carrying capacity and collapse mechanism of such columns are mainly affected by longitudinal reinforcement ratio, transverse reinforcement ratio, axial load ratio, and aspect ratio.

However, those studies did not generally include the low longitudinal reinforcement ratio as 
one of the factors, despite that those practices are also relatively common in the developing countries. Therefore, the complete understanding about its mechanism requires more investigation. The longitudinal and transverse reinforcement ratios and the location of lap splice became the main parameters investigated in this study.

\section{EXPERIMENTAL TEST}

Eight column specimens have been designed to represent structural columns commonly found in developing countries. This study was the extension of previous studies $[14,15]$ which investigated the aspect ratio, the longitudinal reinforcement ratio and the axial load ratio on seismic performance of such columns.

Eight concrete columns specimens had a crosssection area of $150 \times 160 \mathrm{~mm}$ and height of $640 \mathrm{~mm}$ (to the location of lateral load point, with the aspect ratios of $a=4.3$ ). Each four column specimens were reinforced with 4D8 and 4D10 corresponding to the longitudinal reinforcement ratios of $0.75 \%$ and $1.1 \%$ respectively. All stirrups with a diameter of $6 \mathrm{~mm}$ were used for the transverse reinforcements which were spaced at $150 \mathrm{~mm}$ and $250 \mathrm{~mm}$ (equivalent to $0.61 \%$ and $0.36 \%$ of volumetric transverse reinforcement ratio respectively).

Concrete strength ranging 22-27 MPa (an average of $25 \mathrm{MPa}$ ) were observed from concrete compression strength of cylinder concrete and hammer tests on column specimens. The measured yield strength of steel bar with a diameter of $6 \mathrm{~mm}$, $8 \mathrm{~mm}$, and $10 \mathrm{~mm}$ were about $378 \mathrm{MPa}, 433 \mathrm{MPa}$, and $536 \mathrm{MPa}$ respectively, whereas, the corresponding steel ultimate strength were $538 \mathrm{MPa}$, $646 \mathrm{MPa}$, and $824 \mathrm{MPa}$ respectively. The column properties and reinforcement configurations are shown in Table 1 and Fig. 1.

Table 1 Column specimen properties

\begin{tabular}{|c|c|c|c|c|c|c|}
\hline \multirow[t]{2}{*}{ Col. } & \multirow{2}{*}{$\begin{array}{c}\rho_{\mathrm{v}} \\
(\%)\end{array}$} & \multicolumn{2}{|c|}{$\rho_{\mathrm{h}}$} & \multirow{2}{*}{$n$} & \multirow{2}{*}{$\begin{array}{c}\text { Lap } \\
\text { Splice } \\
\text { Region } \\
\end{array}$} & \multirow{2}{*}{$\begin{array}{c}l_{d} \\
(\mathrm{~mm})\end{array}$} \\
\hline & & Area & Vol. & & & \\
\hline L15C & 0.76 & 0.35 & 0.61 & 0.1 & - & - \\
\hline L25C & 0.76 & 0.21 & 0.36 & 0.1 & - & - \\
\hline M15C & 1.10 & 0.35 & 0.61 & 0.1 & - & - \\
\hline M25C & 1.10 & 0.21 & 0.36 & 0.1 & - & - \\
\hline L15SB & 0.76 & 0.35 & 0.61 & 0.1 & Plastic & 200 \\
\hline L15SM & 0.76 & 0.35 & 0.61 & 0.1 & Elastic & 200 \\
\hline M15SB & 1.10 & 0.35 & 0.61 & 0.1 & Plastic & 250 \\
\hline M15SM & 1.10 & 0.35 & 0.61 & 0.1 & Elastic & 250 \\
\hline
\end{tabular}

Note: $\rho_{v}=$ longitudinal reinforcement ratio, $\rho_{h}=$ transverse reinforcement ratio, $n=$ axial load ratio, $l_{d}=$ lap slice length

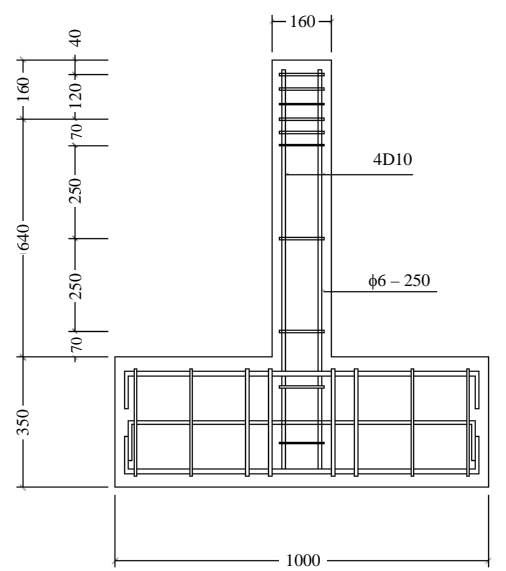

(a) Columns with light transverse reinforcement ratio

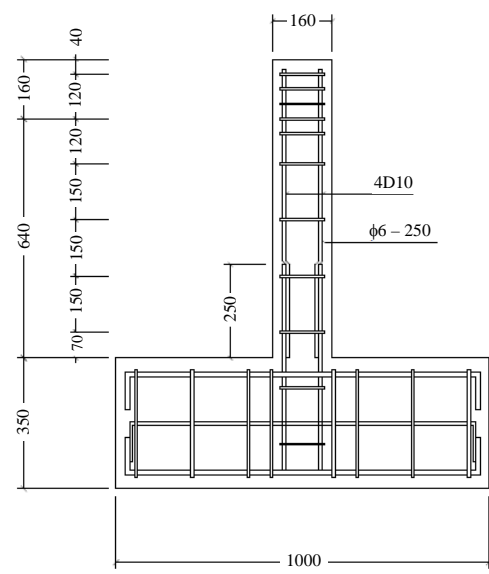

(b) Columns with lap location at bottom of columns

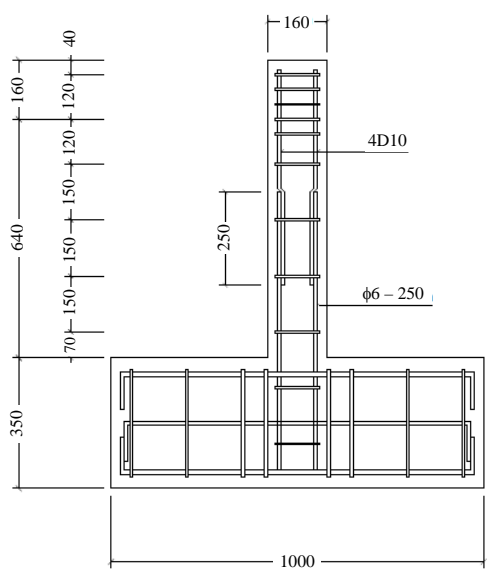

(c) Columns with lap location at mid height of columns

Fig. 1 Typical column specimens.

The lateral quasi-static loading tests were conducted as per ASTM E2126 code. The displacement control sequence was applied by using drift increment of $0.25 \%$ up until reaching drift of $2.0 \%$ and then followed by drift increment of $0.5 \%$ until the occurrence of lateral load failure which was taken at about $20 \%$ load drop of peak 
strength. On each defined discrete drift, the displacement components were measured (consisting of flexural, shear and total displacement) using LVDTs and dial gauges, and crack propagation recorded.

The LVDTs and dial gauges were set to monitor and measure three components of column deformation, i.e., flexural, yield penetration, and shear with configuration as shown in Fig. 2, i.e., no 1-4 for flexural deformation, no 5-7 for total lateral deformation, and no. 8-9 for shear deformation

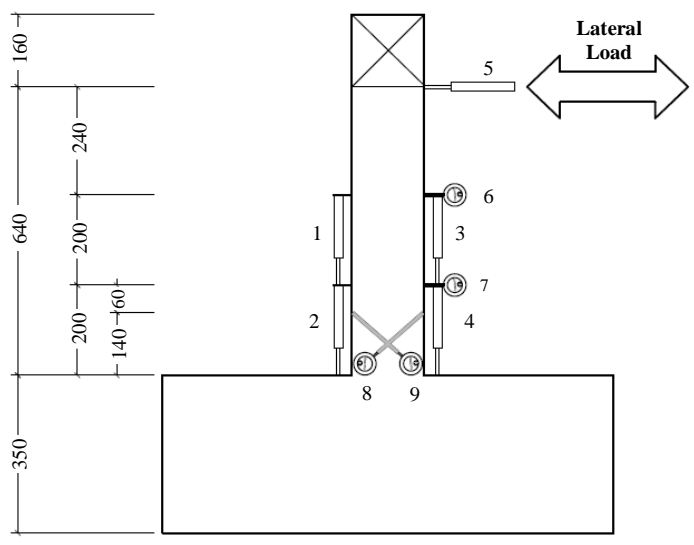

Fig. 2 LVDTs and dial gauges Measurement Setup.

\section{TEST RESULTS}

The outcomes of the tests in terms of peak strength capacity, ductility ratio, load-displacement behavior and collapse mechanism of lightly reinforced concrete when subjected to lateral load are presented in the following subsections.

\subsection{Peak Strength and Ductility Ratio}

The test findings showed interesting results as follows (refer to Fig. 3 and Table 2):

- Specimens with a lower ratio of longitudinal reinforcement ratio tended to have higher ductility ratio. The increase of the longitudinal reinforcement ratio increases the peak strength but decrease the ductility ratio.

- The lateral peak strengths of columns with lap slice located at the half height of the cantilever columns were relatively similar to those of columns with continuous reinforcement. On the other hand, the columns with lap splice located at plastic hinge region showed the smallest of peak lateral strength capacity.

- The continuous reinforcement bar reasonably provided the larger drift capacity, followed by the lap-splice location at column mid-height (elastic region) and bottom (plastic hinge region) respectively.

- The closer the spacing of transverse reinforcement, the higher the ductility ratio due to the higher the confining effect provided by the stirrups.

From the curvature distribution over the column height (refer Fig. 4-5), it shows clearly that by placing the lap splice at column mid-height, the plastic region tends to spread over to the second region from the column-foundation interface. Whilst columns with the continuous bars and lap splice at the bottom of the column had the curvature distribution concentrated more in the plastic hinge area.

\subsection{Load Displacement Behavior and Collapse Mechanism}

The collapse mechanisms and crack propagations of column specimens were observed as follows (refer Fig. 6-7):

- All column specimens exhibited flexuraldominant behavior particularly at the ascending part of the load-displacement curve.

- However, columns with a larger spacing of stirrups tended to developed shear cracks at a later stage following the initial flexural cracks. It showed that the shear strength of columns started to decrease after a certain point and triggered the shear cracks once it is below the flexural strength of columns. It can be attributed to the flexure-shear-critical mechanism of the columns (refer Fig. 6) where the shear strength $V_{n}$ is higher but relatively close to the flexural strength $\left(M_{n} / L\right)$ [7]. On the contrary, the flexure-critical columns with the closer stirrups spacing could maintain the shear strength of columns higher than the flexural capacity despite the shear strength reduction with the progression of drift.

Table 2 Ductility ratio of all column specimens

\begin{tabular}{cccc}
\hline Specimens & $\begin{array}{c}\text { Yield } \\
\text { Drift }\end{array}$ & $\begin{array}{c}\text { Failure } \\
\text { Drift }\end{array}$ & $\begin{array}{c}\text { Ductility } \\
\text { Ratio }\end{array}$ \\
\hline L15C & 0.72 & 4.00 & 5.55 \\
L25C & 0.8 & 3.67 & 4.59 \\
M15C & 1.19 & 4.00 & 3.36 \\
M25C & 1.15 & 3.35 & 2.91 \\
L15SB & 0.92 & 3.67 & 3.99 \\
L15SM & 0.63 & 3.35 & 5.32 \\
M15SB & 0.56 & 2.50 & 4.46 \\
M15SM & 0.68 & 3.00 & 4.41 \\
\hline
\end{tabular}


- The columns with lap slice at mid-height of column showed wider cracking area and more severe concrete spalling compared to columns with lap splice located at the plastic hinge region. The double amount of reinforcement at lap splice location provided higher effectiveness when it was placed at the plastic hinge region (where the maximum moment occurs) compared with if it was located within the elastic area of column (outside the plastic hinge region).

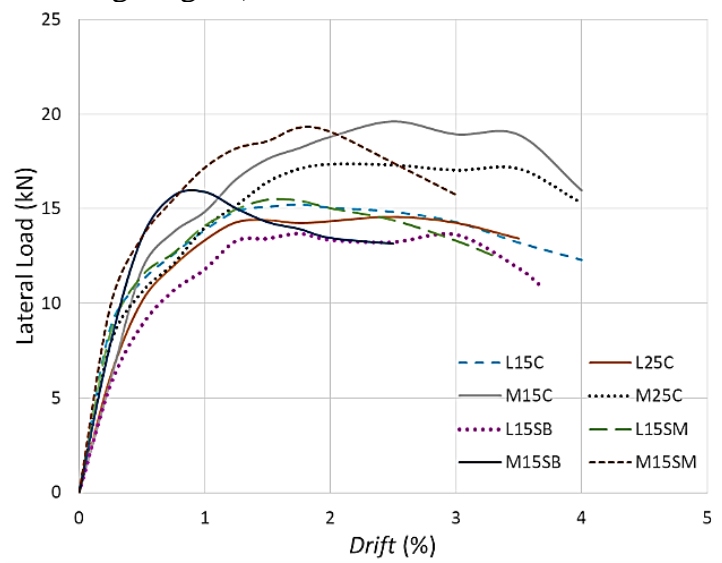

Fig. 3 Lateral load-drift behavior for all column specimens.

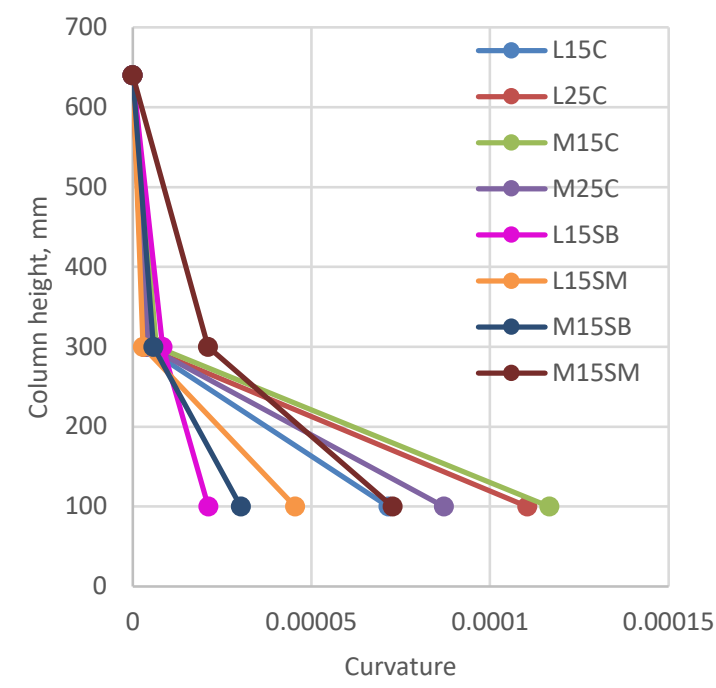

Fig. 4 Curvature distribution over the column height at peak load.

- On the other hand, all columns with lap-splice connection developed higher damage degree compared to columns with continuous bars. It can be attributed to the lack of proper lap splice development lengths in all columns which were purposely designed less than the minimum code requirement in order to investigate the effect of such connection.

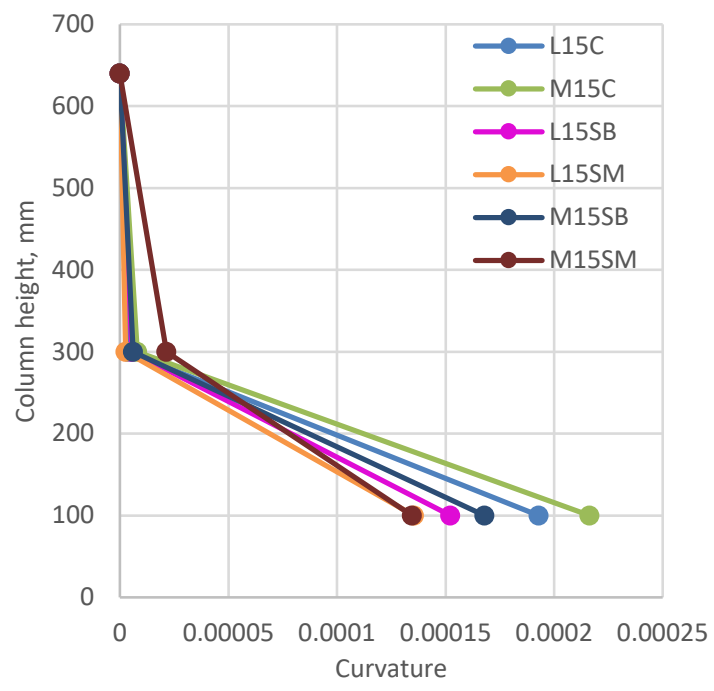

Fig. 5 Curvature distribution over the column height at lateral load failure.

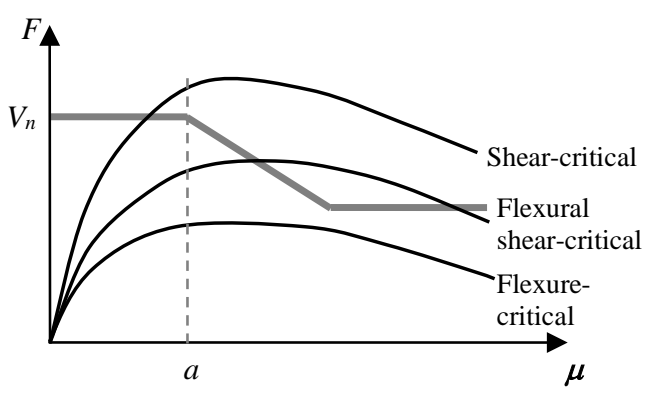

Fig. 6 Curvature distribution over the column height at peak load.

\subsection{Displacement Components}

Furthermore, the measurement of the displacement components of columns (flexural, yield penetration, and shear) showed the different effect of each studied parameters as follows (refer Fig. 8-9):

- The shear deformation was the least component observed in all column specimens up to $5 \%$ of total deformation. It was reasonable since all specimens were designed with light longitudinal reinforcement. However, columns L25C and M25C with lower transverse reinforcement ratio showed larger shear deformation after reaching peak strength. It corroborated the observation of collapse mechanism and crack propagation on column specimens.

- The yield penetration deformation took about $20 \%-50 \%$ of the total deformation. The larger percentage of those was found on columns with lower longitudinal reinforcement. The smaller the diameter of the longitudinal bar, the higher the yield force developed at the bar for the same amount of bending moment, and hence the earlier the slip occurrences between concrete 
and steel.

And certainly, the flexural deformations were reasonably the largest component of deformation ranging $50 \%-70 \%$ of the total deformation due to the nature of flexure-dominant columns.

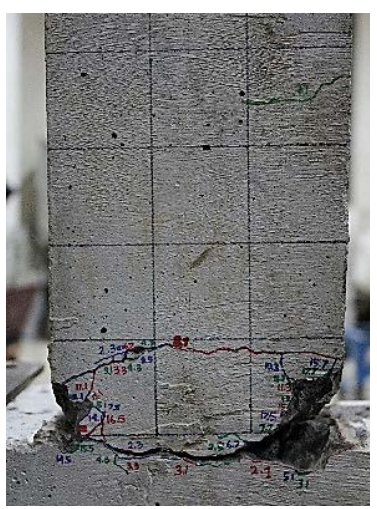

L15C

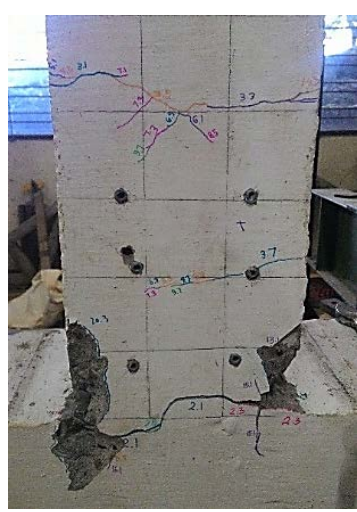

L15SB

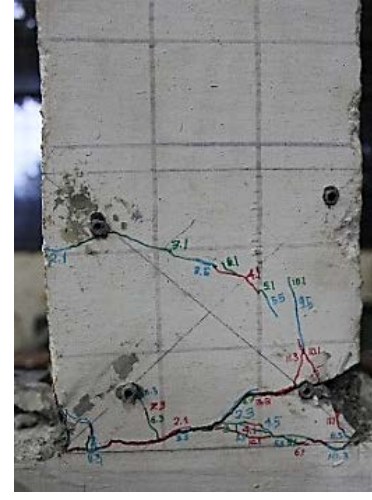

L25C

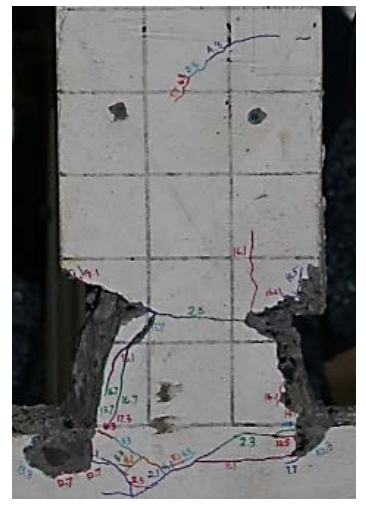

L15SM

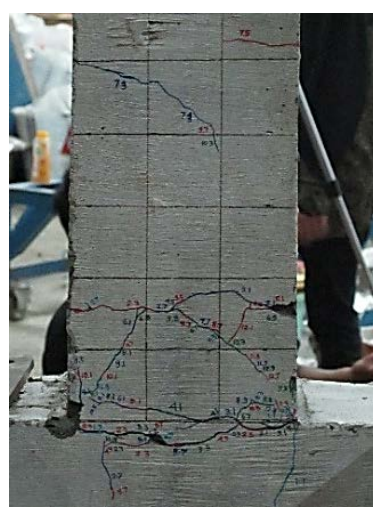

M15C

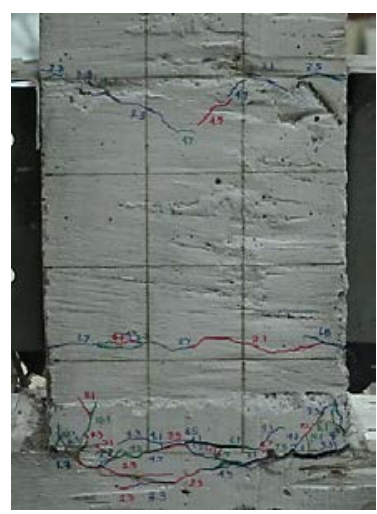

M15SB

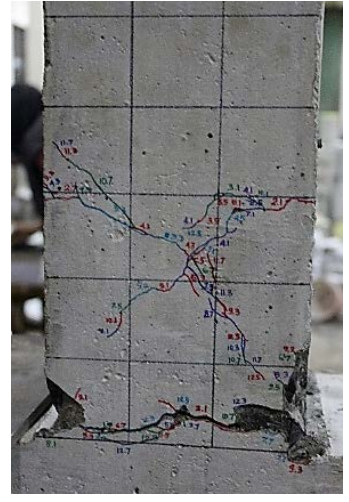

2M25C

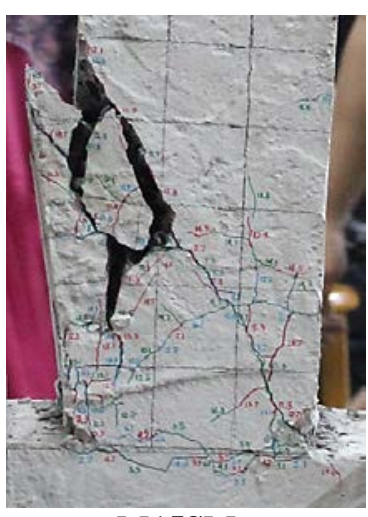

M15SM

Fig. 7 Crack Propagation and collapse mechanism of all column specimens.
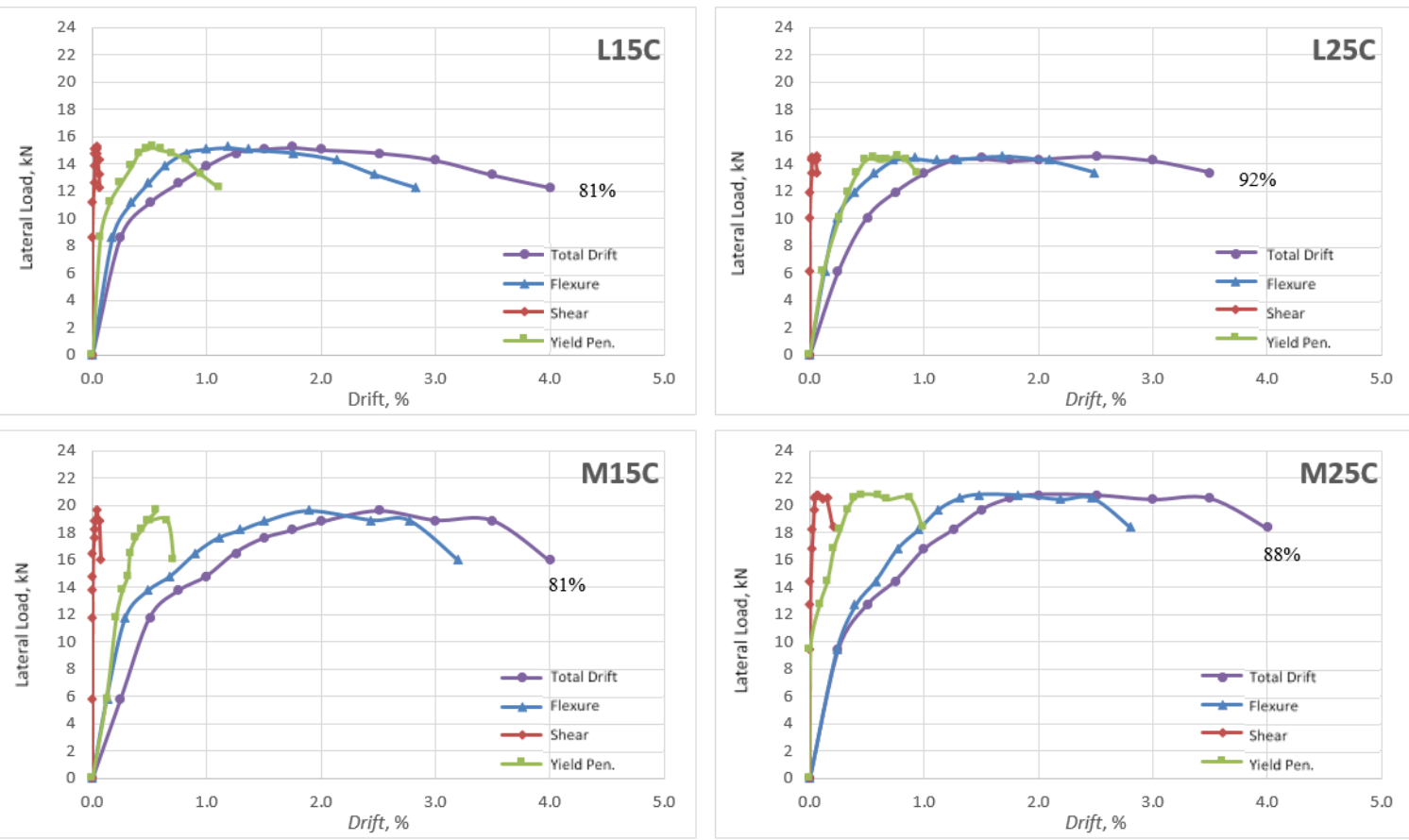

Fig. 8 Displacement components for columns with continuous reinforcement. 

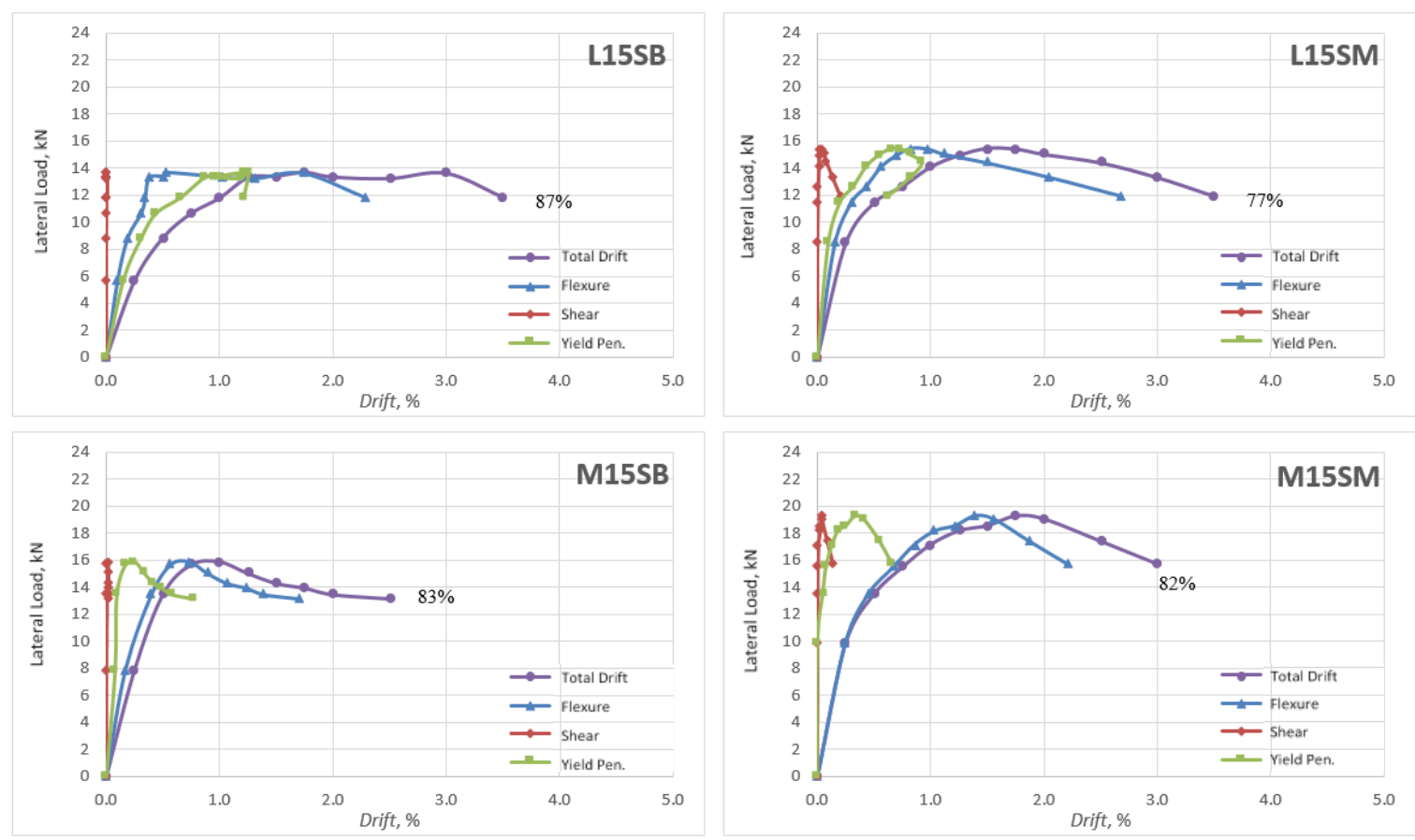

Fig. 9 Displacement components for columns with reinforcement lap-splice.

\section{CONCLUSION}

Reinforced concrete columns with light reinforcement are commonly found in developing countries and low-to-moderate seismic region. An experimental test has been conducted for investigating the seismic performance of such columns. The effect of longitudinal reinforcement ratio, transverse reinforcement ratio, and placing of reinforcement lap splice were the main parameters for studying the load-displacement behavior and collapse mechanism of lightly reinforced concrete columns when subjected to quasi-static lateral load. The findings were as follows:

- The increase of longitudinal reinforcement ratio increases the lateral peak strength, but decrease the ductility ratio, resulted in more flexural-dominant behavior and reduce the yield penetration deformation.

- The increase of transverse reinforcement ratio the higher the ductility ratio, the smaller the shear deformation observed. The closer the shear strength to the flexural strength, columns tend to developed flexure-shear dominant behavior marked with shear collapse mechanism following the initial flexural crack development.

- Placing the lap-splice closer to the plastic hinge region resulted in more concentrated curvature distribution and flexural damage to the bottom of the column which leads to a smaller displacement at the column top. And certainly, the largest displacement capacity can be obtained by using continuous reinforcement

\section{REFERENCES}

[1] Kafle, B., Mohyeddin-Kermani, A., Wibowo, A., A Report on the Visit to the Region Stricken by the Wenchuan Earthquake, Electronic Journal of Structural Engineering, Vol 1, No 1, Appendix B, 2008, pp. 1-40

[2] Shoraka, M.B., Yang, T.Y., Elwood, K.J., Seismic loss estimation of non-ductile reinforced concrete buildings, Earthquake Engineering Structural Dynamics, Vol 42, Issue 2, 2013, pp 297-310

[3] Jeon, J., Lowes, L.N., Roches, R.D., Brilakis, I., Fragility curves for non-ductile reinforced concrete frames that exhibit different component response mechanisms, Engineering Structures, Volume 85, 2015, pp 127-143

[4] Amnart Khampanit' Sutat Leelataviwat' Jensak Kochanin' Pennung Warnitchai, Energy-based seismic strengthening design of non-ductile reinforced concrete frames using bucklingrestrained braces, Engineering Structures, Volume 81, 15 December 2014, Pages 110-122.

[5] Dipti R.Sahoo,D urgesh C. Rai, Seismic strengthening of non-ductile reinforced concrete frames using aluminum shear links as energy-dissipation devices, Engineering 
Structures, Volume 32, Issue 11, November 2010, Pages 3548-3557

[6] Ruilong Han' Yue Li, Johnvan de Lindt, Seismic risk of base isolated non-ductile reinforced concrete buildings considering uncertainties and mainshock-aftershock sequences, Structural Safety, Volume 50, September 2014, Pages 39-56

[7] Romanbabu M. Oinam, Dipti Ranjan Sahoo, Rahul Sindhu, Cyclic Response of Non-ductile RC Frame with Steel Fibers at Beam-Column Joints and Plastic Hinge Regions, Journal of Earthquake Engineering, Volume 18, 2014 Issue 6, Pages 908-928

[8] Sezen, H., "Seismic Response and Modeling of Reinforced Concrete Building Columns, Ph.D. Dissertation, Department of Civil and Environmental Engineering, University of California, Berkeley, 2002.

[9] Rodsin, K., Seismic Performance of Reinforced Concrete Soft-storey Buildings in Low to Moderate Seismicity Regions, Ph.D. Dissertation, Department of Civil and Environmental Engineering, University of Melbourne, Melbourne, 2007.

[10] Griffith, M.C., Wu, Y.F., Oehlers, D.J., Behaviour of Steel Plated RC Columns Subject to Lateral Loading, Advances in Structural Engineering, Vol. 8, No. 4, 2005, pp 333-347.

[11] Nakamura, T., Yoshimura, M., Gravity Load Collapse of Reinforced Concrete Columns with
Brittle Failure Modes, Journal of Asian Architecture and Building Engineering, Vol 1, No. 1, 2002, pp. 21-27. (2002)

[12] Yoshimura, M., Takaine, Y., Nakamura, T., Collapse Drift of Reinforced Concrete Columns, PEER Report 2003/11, Fifth USJapan Workshop on Performance-Based Earthquake Engineering Methodology for Reinforced Concrete Building Structures, Hakone, Japan, 2003, pp. 239-253.

[13] Kogoma, I., Hayashida, T., Minowa, C. Experimental Studies on the Collapse of RC Columns During Strong Earthquake Motions, Tenth World Conference on Earthquake Engineering, Rotterdam, Holland, 1992, pp. 3013-3017.

[14] Wibowo A, Wilson JL, Lam NTK, Gad EF. Drift Performance of Lightly Reinforced Concrete Columns. Engineering Structures Journal, Elsevier, Volume 59, February 2014, pp 522-535.

[15] Wibowo A, Wilson JL, Lam NTK, Gad EF., Drift Capacity of Lightly Reinforced Concrete Columns”. Australian Journal of Structural Engineering, Vol. 15, No. 2, 2014, pp. 131-150.

Copyright (C) Int. J. of GEOMATE. All rights reserved, including the making of copies unless permission is obtained from the copyright proprietors. 